\title{
The studies on characteristics of return to estrus in postpartum dairy cattle
}

\author{
Doo-San Kim ${ }^{1,2}$, Ji-Hwan Lee ${ }^{1}$, Gul-Won Jang ${ }^{1}$, Eun-Jeong Choi ${ }^{1}$, Jin-Ju Kim ${ }^{1}$, Ji-An Lee ${ }^{1}$ and \\ Jun-Kyu Son ${ }^{1, *}$ \\ ${ }^{1}$ Dairy Science Division, National Institute of Animal Science, Cheonan 31000, Korea \\ ${ }^{2}$ Department of Animal Life Science, Kangwon National University, Chuncheon 24341, Korea
}

Received November 18, 2021

Revised December 9, 2021

Accepted December 9, 2021

\section{*Correspondence \\ Jun-Kyu Son \\ E-mail: junkyuson@korea.kr}

\author{
Author's Position and Orcid no. \\ Kim DS, Grad student, \\ https://orcid.org/0000-0002-2528-5386 \\ Lee JH, Researcher, \\ https://orcid.org/0000-0002-0040-3104 \\ Jang GW, Researcher, \\ https://orcid.org/0000-0003-4258-6022 \\ Choi EJ, Researcher, \\ https://orcid.org/0000-0001-5715-2986 \\ Kim JJ, Researcher, \\ https://orcid.org/0000-0003-0772-6341 \\ Lee JA, Researcher, \\ https://orcid.org/0000-0002-1774-4167 \\ Son JK, Researcher, \\ https://orcid.org/0000-0002-6266-3606
}

\begin{abstract}
This study attempted to determine the characteristic features of postpartum dairy cows during their return to estrus. Moreover, it investigated the effects of abnormal ovarian cycles $(\mathrm{AOC})$ on subsequent reproductive performance and the relationship between normal ovarian cycles (NOC) and the blood urea nitrogen (BUN) level postpartum. Incidentally, $56.3 \%$ of the Holstein cows and $66.7 \%$ of the Jersey cows had NOC, whereas the $43.7 \%$ and $33.3 \%$ of the Holstein and Jersey, respectively, had AOC. Within 100 days of calving, the cows with AOC had significantly lower rates of artificial insemination (Al) submission as well as pregnancy and a significantly longer interval to first Al, as compared to that in the cows with NOC. Additionally, the cows with NOC had a significantly higher first Al conception rate than that in the cows with AOC. In this study, of the 32 Holstein cows, 8 resumed their ovarian cycle within 20 days of calving, 10 resumed the cycle with $21-40$ days of calving, 8 within $41-60$ days of calving, while the remaining 6 did not resume their ovarian cycles until 60 days postpartum. Furthermore, the likelihood ratios of incidence of NOC are $0.93,1.94$, and 0.38 , respectively, in the groups with BUN levels < 15, 15-19.9, and $\geq 20 \mathrm{mg}$ / dl. In conclusion, AOC postpartum adversely affects reproductive performance such as $\mathrm{Al}$ submission rate, pregnancy rate, interval to first $\mathrm{Al}$ and first $\mathrm{Al}$ conception rate; moreover, an increase or decrease in the BUN levels beyond $15-19.9 \mathrm{mg} / \mathrm{dL}$ leads to the AOC postpartum.
\end{abstract}

Keywords: BUN, ovarian cycles, postpartum, progesterone

\section{INTRODUCTION}

The conclusion and implementation of the Free Trade Agreement (FTA) resulted in an increase in competitiveness and expansion of product importation. However, the massive import of inexpensive dairy products caused the local dairy industry to be devastated.

Over times, the breeding scale of dairy cattle has gradually become industrialized, and there has been an increased yield of milk production; however, the reproductive efficiency of the dairy cattle has continuously decreased (Roche et al., 2000; Lucy, 2001). For instance, in the United States, the reproductive efficiency seems to be decreasing by approximately 6\% every year (NAHMS, 1998). Therefore, to ensure success amidst this competitiveness, especially at a time when detection of estrus is increasingly difficult and reproductive efficiency is continuously decreasing, it is necessary to understand the 
breeding status of dairy farms. Moreover, this decline in reproductive efficiency, leads to economic losses in the dairy farms, especially the replacement cost of culling cows that have low milk production or are repeatbreeders. A previous study reports that high estrus detection rate, maintenance of the first service, and high conception rate after calving are necessary to obtain an economically ideal 12-month-long calving interval (Pelissier, 1976). However, the high-producing cows suffer from various conditions, such as delayed return to estrus, abnormal expression of estrus, and low conception rate (Wiltbank et al., 2006). Furthermore, there are increasing incidences of non-estrus and silent estrus, particularly due to physiological and environmental changes, and the delayed ovulation and decreased conception rate is causing a significant problem in dairy cows (Rounsaville et al., 1979; Pankowski et al., 1995; Austin et al., 1999).

It has been reported that the reproductive functions of dairy cows can be negatively affected after calving (Beam and Butler, 1999). In fact, there are many instances of abnormal ovarian cycles (AOC) after calving, including prolonged luteal phase (PLP) (Lamming and Darwash, 1998; Opsomer et al., 1998; Shrestha et al., 2004a) and a delay in the first ovulation; moreover, the delayed resumption of ovarian cycles can negatively affect the conception rate in dairy cows. Furthermore, dairy cows exhibiting such AOC during the postpartum period, have more days open, a higher number of services per conception, a lower first service conception rate, and a reduced total conception rate, as compared to that in the cows with normal ovarian cycles (NOC) after calving (Lamming and Darwash, 1998; Shrestha et al., 2004b). Therefore, in the postpartum period, high-producing cows may suffer from delayed return to estrus, abnormal expression of estrus, and a continuous decrease in the conception rate (Wiltbank et al., 2006).

Several previous studies on the resumption of ovarian cycles after calving (Opsomer et al., 1998; Shrestha et al., 2004a) have demonstrated a delay in the first ovulation after the calving period as well as an extension of the luteal phase post-ovulation in the high-producing cows. Additionally, the delay in the first ovulation postpartum has been attributed to a lack of energy during the early lactating period (Butler, 2001). However, it is not easy to determine the energy states during breeding. Incidentally, the level of blood urea nitrogen (BUN) reflects the amount and degradability of protein as well as the balance between protein and energy (Ferguson et al, 1993). Therefore, BUN has been used as an indicator of the balance in nutrition management, and there have been reports about the relation between BUN and the conception rate of dairy cows (Ferguson et al., 1993; Butler et al., 1996; Park et al., 1997). Moreover, even though low conception rate is the most important factor for the culling of dairy cows (Rajala-Schultz and Gröhn, 1999), it has not been studied in a domestic environment. Therefore, the objective of this study was to characterize the return to estrus after calving, to examine the effects of ovarian cycles after calving on subsequent reproductive performance, and to explore the relationship between the BUN level and ovarian cycles in dairy cows after calving.

\section{MATERIALS AND METHODS}

\section{Animal selection}

There were 47 postpartum cows, namely 32 Holstein and 15 Jersey cows, used for the experiments conducted from 2019 to 2021 in the Department of Dairy Science, National Institute of Animal Science. All experimental animals were housed up to 100 days after calving in freestalls, fed on a Total Mixed Ration (TMR) diet (according to the Korean feeding standards for dairy cattle), and milked twice daily (08:00 a.m. and 05:00 p.m.) during the experiment period.

\section{Blood collection and progesterone (P4) analysis}

From the $2^{\text {nd }}$ to $12^{\text {th }}$ week after calving, blood was collected after every 7 days from the jugular veins of the 47 dairy cows between 10:00 and 11:00 a.m. using a $10 \mathrm{~mL}$ vacutainer tube with heparin. The blood samples were immediately transported to the laboratory, and within 6 hours, the plasma was separated by centrifugation at 3,000 rpm for 10 minutes. Subsequently, the plasma samples were stored at $-20^{\circ} \mathrm{C}$ until further assay. Plasma P4 concentrations were analyzed using an automated immunoassay analyzer (Roche E-170, Switzerland) in all dairy cows. The BUN levels were analyzed using a chemistry analyzer (Vetscan VS2, USA) in Holstein cows.

\section{Estrus detection and artificial insemination (AI)}

A Kamar heatmount detector (Kamar Inc., Steamboat Springs, CO) was attached to the tail-head of each Hol- 
stein cow after calving, and the estrus status was monitored before and after milking twice daily. The dairy cows were determined to be in estrus if there was a visual color change (activation) of the heat detection resulting from the standing heat of the cows, or if they displayed secondary estrus symptoms, such as swelling and reddening of the vulva and mucus discharge. After 40 days of calving, i.e., the voluntary waiting period (VWP), the cows in the estrus phase were subjected to AI. After 60 days of AI, pregnancy was determined by rectal palpation. None of the cows received hormone treatment during the experiment period.

\section{Different types of ovarian cycles and calculation methods of reproductive indices}

The dairy cows were identified to be exhibiting luteal activities when the $\mathrm{P}_{4}$ concentration was $\geq 1 \mathrm{ng} / \mathrm{mL}$ in two successive plasma samples collected in the same week. Additionally, the ovulation day was determined to be 5 days prior to day when the $\mathrm{P}_{4}$ concentration first increased to $\geq 1 \mathrm{ng} / \mathrm{mL}$ (Shrestha et al., 2004a). The postpartum resumption of ovarian cycles was defined as ovulation followed by regular cycles consisting of an approximately 2-week-long luteal phase and 1-week-long follicular phase. As shown in Fig. 1, the resumption of the

1. Normal resumption of ovarian cycles

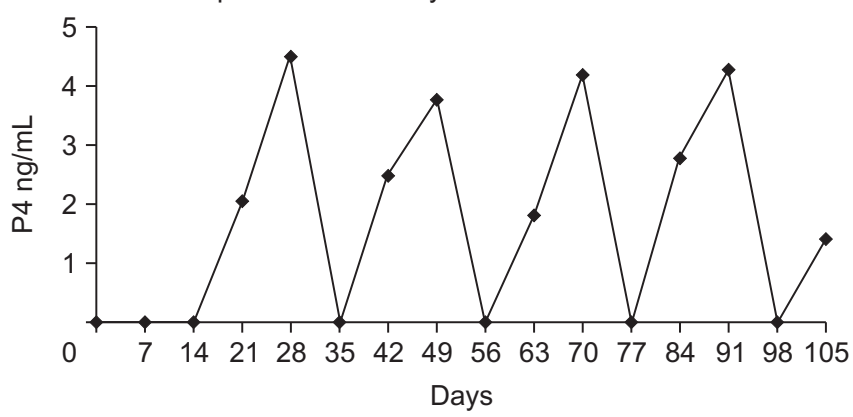

3. Delayed resumption Type II (delayed first ovulation)

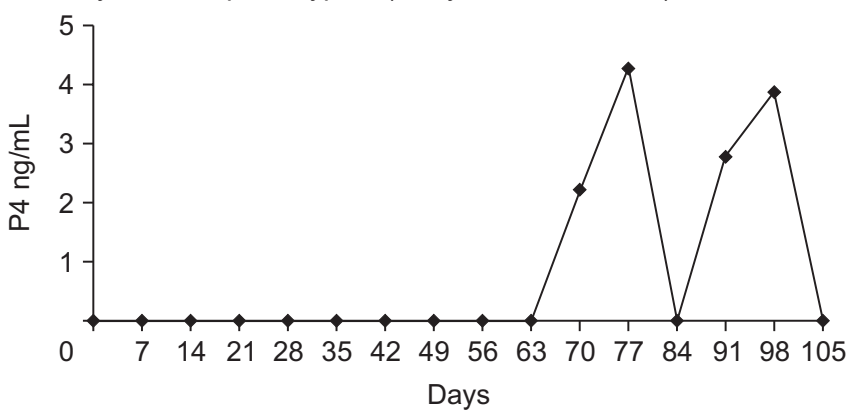

ovarian cycles was, according to the following characteristics of the change in P4 concentration.

1) Normal resumption of ovarian cycles: Ovulation occurred $\leq 40$ days after calving, followed by regular ovarian cycles.

2) Delayed resumption of ovarian cycles: Ovulation followed by regular ovarian cycles did not resume until after $>40$ days of calving. The delayed resumption of the ovarian cycle was subdivided as follows, based on ovarian function.

2-1) Delayed resumption Type I: one or more ovarian cycles with luteal activity $>20$ days.

2-2) Delayed resumption Type II: first ovulation did not occur until $>40$ days after calving.

2-3) Delayed resumption Type III: absence of luteal activity for at least 14 days between the first and second luteal phases.

The reproductive indices were calculated as follows:

- AI submission rate within $\leq 100$ days after calving (\%): The proportion of the total number of dairy cows to be bred that were inseminated within 100 days after calving, expressed as a percentage.

- Conception rate within $\leq 100$ days (\%): The proportion of the total number of inseminated dairy cows that conceived within 100 days after calving, expressed as a

2. Delayed resumption Type I (prolonged luteal phase)

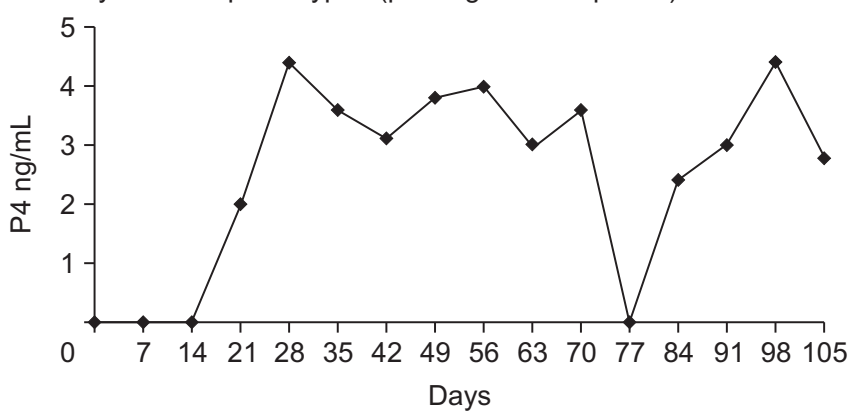

4. Delayed resumption Type III (cessation of cycles)

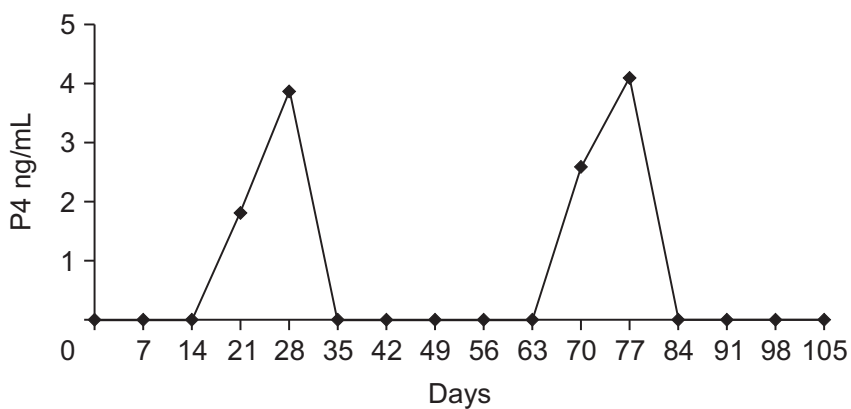

Fig. 1. Different types of resumption of ovarian cycles with representative progesterone profiles in dairy cows. 
percentage (irrespective of whether a cow was inseminated once or more than once)

- Pregnancy rate within $\leq 100$ days (\%): The proportion of the total number of dairy cows to be bred that conceived within 100 days after calving, expressed as percentage.

- Dairy cows that did not get pregnant within 210 days: The proportion of the total number of dairy cows to be inseminated that did not get pregnant within $\leq 210$ days after calving.

- Interval to first AI (days): The number of days between calving and the first $\mathrm{AI}$ among the dairy cows that were inseminated within 210 days after calving.

- First AI conception rate (\%): The proportion of the total number of artificially inseminated dairy cows that conceived after their first AI (within 210 days), expressed as a percentage.

- Calving to conception interval [mean \pm standard error of the mean (S.E.)]: The average number of days from the delivery date to the final $\mathrm{AI}$ at which a dairy cow gets pregnant.

\section{Statistical analysis}

The data were analyzed using the SAS program. Statistical significance related to ovarian cycles was analyzed using the Chi-square test and Student's t-test. The differences were considered to be statistically significant for $p<0.05$. The likelihood ratio was calculated, according to the protocol described by in Ferguson et al. (1993), to determine the relationship between the BUN level and the AOC after calving.

\section{RESULTS and DISCUSSION}

As represented in Fig. 1, the different types of resump-

Table 1. Incidence of different types of ovarian cycles during the preservice period in Holstein cows after calving

\begin{tabular}{lcc}
\hline & No. of cows & Percentage \\
\hline Normal ovarian cycles & 18 & 56.3 \\
Abnormal ovarian cycles & & \\
$\quad$ Prolonged luteal phase (Type I) & 4 & 12.5 \\
Anovulation (Type II) & 7 & 21.9 \\
Cessation of cycles (Type III) & 3 & 9.4 \\
Sub-total (abnormal ovarian cycles) & 14 & 43.7 \\
Total & 32 & 100.0 \\
\hline
\end{tabular}

tion of ovarian cycles in postpartum dairy cows, namely Jersey and Holstein, are expressed as changes in their respective $\mathrm{P}_{4}$ concentrations. In this study, 14 (43.7\%) Holstein cows and 5 (33.3\%) Jersey cows exhibit AOC after calving (Table 1 and 2). Incidentally, this delay in the resumption of regular cycles is higher than that reported in certain previous studies (Lamming and Darwash, 1998; Opsomer et al., 1998) and lower than that observed in a study on high-producing herds in Japan (Shrestha et al., 2004a). In particular, the incidence of a prolonged luteal phase (delayed resumption Type I) seems to be a major factor in the overall increased occurrence of AOC. Although Bulman and Lamming (1977) defined the delay in the resumption of the ovarian cycles slightly differently, their study demonstrated that a prolonged luteal phase led to only $1.5 \%$ of these delays. This rate is quite low, as compared to that observed in the present study $(21.9 \%$ of Holstein and $13.3 \%$ of Jersey cows) and in another previous study (35.2\%; Shrestha et al., 2004b), thereby indicating that there has been a significant change in the factors causing the delay in resumption of ovarian cycles in postpartum dairy cows over the past 40 years. However, the proportion of dairy cows that underwent delayed first ovulation after calving (delayed resumption Type II) in this study is similar to that reported in the results of previous studies. Furthermore, the incidence of cessation of cycles (delayed resumption Type III) is $<5 \%$ in this study as well as in some previous studies (Opsomer et al., 1998; Shrestha et al, 2004a); however, Lamming and Darwash (1998) reported this frequency to be $>10 \%$.

Incidentally, the cows in this study as well as in the experiments conducted by Shrestha et al. (2004a) were housed in free-stalls, while in other similar studies, the cows were housed by grazing management in the pastures (Lamming and Darwash, 1998; Opsomer et al., 1998). It

Table 2. Incidence of different types of ovarian cycles during the preservice period in Jersey cows after calving

\begin{tabular}{lcc}
\hline & No. of cows & Percentage \\
\hline Normal ovarian cycles & 10 & 66.7 \\
Abnormal ovarian cycles & & \\
$\quad$ Prolonged luteal phase (Type I) & 2 & 13.3 \\
Anovulation (Type II) & 2 & 13.3 \\
Cessation of cycles (Type III) & 1 & 6.7 \\
Sub-total (abnormal ovarian cycles) & 5 & 33.3 \\
Total & 15 & 100.0 \\
\hline
\end{tabular}


is commonly known that the risk of $\mathrm{AOC}$ is lower than the housing management system (Opsomer et al., 2000). Shrestha et al. (2004b) revealed that the high rate of abnormal resumption of ovarian cycles is due to the testing of only high-yielding cows in their experiment.

Among the 47 postpartum cows studied during this experiment, 15 were Jersey cows, of which 10 (66.7\%) exhibit normal resumption of ovarian cycles after calving, and $5(33.3 \%)$ exhibit a delayed resumption of ovarian cycles. Particularly, it was noted that 2 (13.3\%) of them show delayed resumption Type I, 2 (13.3\%) show delayed resumption Type II, and only 1 (6.7\%) shows delayed resumption Type III. Among the 32 Holstein cows in this study, $8(25.0 \%)$ resumed their ovarian cycle within 20 days of calving, whereas $6(18.8 \%)$ did not resume their ovarian cycle until after 60 days of calving (Fig. 2). More-

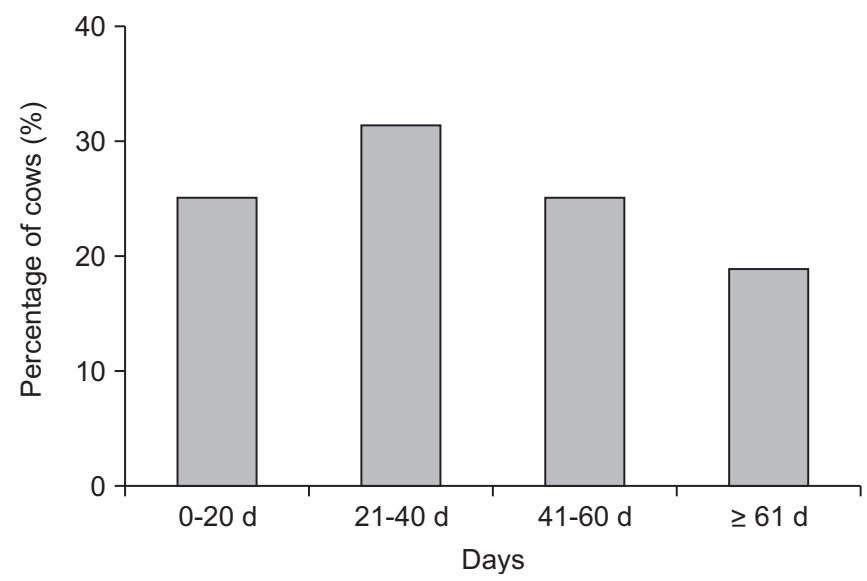

Fig. 2. Percentage of cows that resumed ovarian cycles postpartum at different postpartum intervals. over, $10(31.3 \%)$ of them resumed their ovarian cycles between 21 and 40 days after calving, while 8 of them resumed their ovarian cycles within 41 to 60 days after calving. Therefore, out of the 32 Holstein cows, 18 (56.2\%) exhibit normal resumption of ovarian cycles after calving, while the remaining 14 (43.8\%) exhibit a delayed resumption of ovarian cycles. Likewise, it was noted that $4(12.5 \%)$ of them show delayed resumption type I, 7 (21.9\%) show delayed resumption type II, and 3 (9.4\%) show delayed resumption type III.

Incidentally, previous studies have reported that the incidence of delayed resumption Type I with an extended luteal phase is a major factor in the overall increased occurrence of delayed ovarian cycles in Holstein cows. However, in Jersey cows (13.3\%) this was lower than Holstein cows. Since the high rate of abnormal resumption of ovarian cycles has been attributed to the selective study of only high-producing cows (Shrestha et al., 2004a), further studies are necessary to examine the milk production and return to estrus in Jersey cows. We believe that the differences in the degree of abnormal resumption of ovarian cycles may be due to environmental factors and differences in milk production.

Within 100 days of calving, $88.9 \%$ of the Holstein cows with normal resumption of ovarian cycles were selected for AI, whereas a significantly lower $(p<0.01)$ proportion (54.5\%) of the ones with AOC, such as prolonged luteal phase, were subjected to AI (Table 3). Interestingly, there are no significant differences $(p>0.05)$ between the conception rates of the Holstein cows with normal and abnormal resumption of ovarian cycles $(43.7 \%$ and $33.3 \%$, respectively), as observed within 100 days of calv-

Table 3. Reproductive performance of cows with normal ovarian cycles, prolonged luteal phase and anovulation during the pre-service after calving

\begin{tabular}{lcc}
\hline & Normal ovarian cycles & Abnormal ovarian cycles \\
\hline No. of cows examined & 18 & 11 \\
No. of cows inseminated $\leq 100$ days postpartum & 16 & 6 \\
Al submission rate $\leq 100$ days postpartum (\%) & $88.9(16 / 18)^{* *}$ & $40.0(6 / 11)$ \\
Conception rate $\leq 100$ days postpartum (\%) & $43.7(7 / 16)$ & $33.3(2 / 6)$ \\
Pregnancy rate $\leq 100$ days postpartum (\%) & $38.9(7 / 18)^{*}$ & $18.2(2 / 11)$ \\
No. of cows inseminated $\leq 210$ days postpartum & 17 & 7 \\
Mean \pm S.E.) interval to first Al (days) & $72.4 \pm 3.42^{* *}$ & $123.5 \pm 8.26$ \\
First Al conception rate (\%) & $41.2(7 / 17)^{*}$ & $14.3(1 / 7)$ \\
Calving to conception interval (days) for pregnant cows (mean \pm S.E.) & $112.3 \pm 8.25$ & $156.1 \pm 17.34$ \\
\hline
\end{tabular}

${ }^{*} p<0.05$.

${ }^{* *} p<0.01$, differ with that of normal resumption cows. 
ing. However, the pregnancy rate, as calculated within 100 days after calving, is significantly different between the cows with normal and AOC $(38.9 \%$ and $18.2 \%$, respectively), mainly because fewer cows with delayed resumption of ovarian cycles were selected for AI, as compared to the number of cows with NOC. Incidentally, the mean interval until the first AI is significantly different $(p<$ 0.01 ) between the herd of dairy cows with NOC and the herd with AOC (72.4 and 123.5 days, respectively); additionally, the calving to conception interval for pregnant cows was 112.3 and 156.1 days for cows with normal and abnormal ovarian cycles, respectively. Moreover, the first AI conception rate is significantly lower $(p<0.05)$ in the cows with delayed resumption Type I (14.3\%), as compared to that in the cows with NOC (41.2\%) (Table 3). Therefore, the reproductive efficiency of dairy cows with AOC, including prolonged luteal phase and delayed ovulation, is lower in comparison to that of the cows with NOC. Particularly, the cows of the delayed resumption Type I group exhibit a lower AI submission rate within 100 days, first AI conception, and pregnancy rate than that of cows with NOC. Additionally, the mean interval to first $\mathrm{AI}$ and calving to conception interval for pregnant cows are longer in case of the cows with AOC than in the ones with NOC. These results are in agreement with previous reports (Lamming and Darwash, 1998; Shrestha et al., 2004b; Park et al., 2006). Furthermore, the dairy cows that exhibit anovulation have lower conception and pregnancy rates, as calculated within 100 days, than those of the dairy cows with NOC, and the mean interval until first $\mathrm{AI}$ as well as calving to conception interval for pregnant cows are longer than that of the pregnant cows belonging to the delayed resumption Type I group. Additionally, the dairy cows with AOC tend to show an increase in the number of AIs per conception and a decreased in the first AI conception rate, as compared to that in the dairy cows with NOC. These results are consistent with the report of Lamming and Darwash (1998), but different from the report of Shrestha et al. (2004b), which demonstrated an extreme decrease in the first $\mathrm{AI}$ conception rate (0\%).

The present study has not investigated the relationship between the abnormalities associated with the resumption of ovarian cycles in postpartum dairy cows and the reduced breeding efficiency. However, Shrestha et al. (2004b) indicated that in dairy cows with prolonged luteal phase, there is an abnormal uterine environment, includ- ing uterine contamination and delayed recovery, which contributes to their low conception rates (Opsomer et al., 1998; Opsomer et al., 2000). Furthermore, the dairy cows with symptoms of anovulation exhibit a decreased body condition score (BCS) during the early lactation period, as compared to that of the cows with NOC (Opsomer et al., 2000; Shrestha et al., 2004b). We believe that these anovulatory dairy cows are in severe negative energy states during the early lactation period, and the BCS decline increases the risk for low conception rate in this period (Butler, 2001). Interestingly, pregnant cows have a higher progesterone level during their ovarian cycles, both before and after fertilization, as compared to that of nonpregnant cows. We observed that the dairy cows with AOC have a lower blood progesterone concentration due to the lack of expression of ovarian cycles before fertilization, and this may be responsible for the decrease in their conception rates.

The BUN level reflects the amount of protein intake, the decomposition of proteins, and the balance between protein and energy levels in the body (Ferguson et al., 1993). Therefore, it has been used as an indicator of the adequacy of nutrition management, and certain other studies have established an association between the BUN level and the conception rate of dairy cows (Ferguson et al., 1993; Butler et al., 1996; Park et al., 1997). It is common for BUN to be maintained at an appropriate level after its initial increase for several weeks during the early lactation stage after calving (Carroll et al., 1988; Ferguson et al., 1988; Canfield et al., 1990; Park et al., 1997). Therefore, for BUN levels to be used as an indicator for determining the adequacy of feed management, it is vital to consider the timing of BUN measurement. In majority of the cases where the BUN level is lower than the standard value, it is considered to be due to insufficient feed intake; on the contrary, if it is higher than the standard value, then it is generally interpreted to be due to a lack of energy in the feed. Therefore, by determining the BUN level, the energy status of the animal at that time can be inferred. In this study, BUN level was determined as the average value obtained between 40 and 70 days after calving. Table 4 shows the likelihood ratio of the normal ovarian cycle occurrence by categorizing the BUN level into groups of $<15,15-19.9$, and $\geq 20 \mathrm{mg} / \mathrm{dL}$, and the respective likelihood ratios are $0.93,1.94$, and 0.38 . Therefore, when the BUN level is $<15 \mathrm{mg} / \mathrm{dL}$ or $>19.9 \mathrm{mg} / \mathrm{dL}$, the incidence 
Table 4. Likelihood ratio for cows categorized by blood urea nitrogen (BUN) levels

\begin{tabular}{lcccc}
\hline \multirow{2}{*}{ BUN category $(\mathrm{mg} / \mathrm{dL})$} & Cows $(\mathrm{n})$ & \multicolumn{3}{c}{ Percentage $^{\mathrm{a}}$} \\
\cline { 3 - 4 } & & Normal cycle & Abnormal cycle & Likelihood ratio $^{\mathrm{b}}$ \\
\hline$<15$ & 22 & 66.7 & 71.4 & 0.93 \\
$15-19.9$ & 7 & 27.8 & 14.3 & 1.94 \\
$20 \leq$ & 3 & 5.5 & 14.3 & 0.38 \\
\hline
\end{tabular}

aPercentage of total cows within each BUN category.

${ }^{b}$ Percentage of normal cows divided by the percentage of abnormal.

of a normal ovarian cycle is lowered.

When a postpartum dairy cow begins lactating, the demand for energy increases rapidly, and with the increase in the milk yields, the energy shortage also increases. In fact, previous studies have reported that the first ovulation after calving is delayed due to lack of energy (Beam and Butler, 1999; Butler, 2001). The first ovulation after calving indicates that follicular development has resumed, and it can be completed after recovering from the hormonal state at the end of pregnancy. Incidentally, regardless of energy shortage, postpartum follicular waves appear around 5 to 7 days after calving in response to an increase in the plasma concentration of follicle-stimulating hormone (FSH) (Butler, 2003). The ovulation of these dominant follicles developed by the follicular waves in the early lactation period depends on the secretion of luteinizing hormone (LH) (Jolly et al., 1995). In fact, it has been established that cows that do not ovulate have a much lower frequency of LH release during the first postpartum follicular wave, as compared to that in the cows where dominant follicles undergo ovulation (Beam and Butler, 1999; Butler, 2001). Interestingly, the difference between dairy cows with respect to the level and duration of energy shortage that determines the resumption of their estrus cycles after calving depends on the variation in dry matter intake during the early lactation period (Villa-Godoy et al., 1988; Staples et al., 1990). Based on the results of this study, it can be inferred that if the BUN level is identified at 40-70 days after calving, then it can help to evaluate whether the problem in the resumption of ovarian cycles is due to difficulty in estrus detection or a physiological abnormality due to poor nutritional status.

\section{CONCLUSION}

This study attempted to define the characteristics of return to estrus in postpartum dairy cows, and it investigat- ed the effects of abnormal resumption of ovarian cycles after calving on the subsequent reproductive performance of the dairy cows in a domestic environment; additionally, it established a relationship between the resumption of ovarian cycles and the BUN level after calving. Abnormal ovarian cycles adversely affect subsequent reproductive performance, such as AI submission rate, pregnancy rate, interval to first AI, and first $\mathrm{AI}$ conception rate in postpartum dairy cows. Moreover, a BUN level that is $<15 \mathrm{mg} / \mathrm{dL}$ or $>19.9 \mathrm{mg} / \mathrm{dL}$ leads to a decrease in the incidence of normal ovarian cycle.

In conclusion, we suggest that these abnormal ovarian cycles lead to poor reproductive performance, and proper nutritional management can prevent abnormal resumption of ovarian cycles and improve the reproductive efficiency in the transition as well as early lactation period.

Author Contributions: Conceptualization, J.K.S.; data curation, D.S.K., J.K.S.; formal analysis, J.K.S.; investigation, D.S.K., J.H.L., E.J.C., J.J.K., J.A.L., J.K.S.; methodology, J.K.S.; project administration, D.S.K., J.K.S.; resources, J.K.S., G.W.J.; supervision, J.K.S.; writing - original draft, D.S.K.; writing - review \& editing, D.S.K., J.K.S.

Funding: This work was carried out with the support of the "Cooperative Research Program for Agriculture Science $\&$ Technology Development (Project title: The study on the utilization of Jersey cattle for domestic supply and superior herd construction, Project No. PJ014392)" Rural Development Administration, Republic of Korea.

Ethical Approval: Animal care and experimental procedures were conducted according to the guidelines of the National Institute of Animal Science (NIAS; Rural Development Administration, Cheonan 31000, Republic of Korea), Animal Care and Use Committee (Approval number: NIAS-2020124). 
Consent to Participate: Not applicable.

Consent to Publish: Not applicable.

Availability of Data and Materials: All data presented in this are available on request from the corresponding authors. The raw data supporting the conclusions of this article will be made available by the authors, without undue reservation.

Acknowledgements: This study was supported by 2021 collaborative research program between university and Rural Development Administration, Republic of Korea.

Conflicts of Interest: No potential conflict of interest relevant to this article was reported.

\section{REFERENCES}

Austin EJ, Mihm M, Ryan MP, Williams DH, Roche JF. 1999. Effect of duration of dominance of the ovulatory follicle on onset of estrus and fertility in heifers. J. Anim. Sci. 77:22192226.

Beam SW and Butler WR. 1999. Effects of energy balance on follicular development and first ovulation in postpartum dairy cows. J. Reprod. Fertil. Suppl. 54:411-424.

Bulman DC and Lamming GE. 1977. Cases of prolonged luteal activity in the non-pregnant dairy cow. Vet. Rec. 100:550552.

Butler WR. 2001. Nutritional effects on resumption of ovarian cyclicity and conception rate in postpartum dairy cows. BSAP Occas. Publ. 26:133-145.

Butler WR. 2003. Energy balance relationships with follicular development, ovulation and fertility in postpartum dairy cows. Livest. Prod. Sci. 83:211-218.

Butler WR, Calaman JJ, Beam SW. 1996. Plasma and milk urea nitrogen in relation to pregnancy rate in lactating dairy cattle. J. Anim. Sci. 74:858-865.

Canfield RW, Sniffen CJ, Butler WR. 1990. Effects of excess degradable protein on postpartum reproduction and energy balance in dairy cattle. J. Dairy Sci. 73:2342-2349.

Carroll DJ, Barton BA, Anderson GW, Smith RD. 1988. Influence of protein intake and feeding strategy on reproductive performance of dairy cows. J. Dairy Sci. 71:3470-3781.

Ferguson JD, Blanchard T, Galligan DT, Hoshall DC, Chalupa W. 1988. Infertility in dairy cattle fed a high percentage of protein degradable in the rumen. J. Am. Vet. Med. Assoc. 192: 659-662.

Ferguson JD, Galligan DT, Blanchard T, Reeves M. 1993. Serum urea nitrogen and conception rate: the usefulness of test information. J. Dairy Sci. 76:3742-3746.
Jolly PD, McDougall S, Fitzpatrick LA, Macmillan KL, Entwistle KW. 1995. Physiological effects of undernutrition on postpartum anoestrus in cows. J. Reprod. Fertil. Suppl. 49:477492.

Lamming GE and Darwash AO. 1998. The use of milk progesterone profiles to characterise components of subfertility in milked dairy cows. Anim. Reprod. Sci. 52:175-190.

Lucy MC. 2001. Reproductive loss in high-producing dairy cattle: where will it end? J. Dairy Sci. 84:1277-1293.

Opsomer G, Coryn M, Deluyker H, de Kruif A. 1998. An analysis of ovarian dysfunction in high yielding dairy cows after calving based on progesterone profiles. Reprod. Domest. Anim. 33:193-204.

Opsomer G, Gröhn YT, Hertl J, Coryn M, Deluyker H, de Kruif A. 2000. Risk factors for post partum ovarian dysfunction in high producing dairy cows in Belgium: a field study. Theriogenology 53:841-857.

Pankowski JW, Galton DM, Erb HN, Guard CL, Gröhn YT. 1995. Use of prostaglandin F2 alpha as a postpartum reproductive management tool for lactating dairy cows. J. Dairy Sci. 78: 1477-1488.

Park SB, Kim HS, Kim CK, Chung YC, Lee JW, Kim CH. 1997. Relation of conception rate and plasma urea nitrogen in dairy cattle. Korean J. Anim. Reprod. 21:185-189.

Park SB, Son JK, Park SJ, Baek KS, Jeon BS, Ahn BS, Kim HS, Park CK. 2006. Effect of abnormal ovarian cycle postpartum on subsequent reproductive performance in Holstein cows. Reprod. Dev. Biol. 30:213-218.

Pelissier CL. 1976. Dairy cattle breeding problems and their consequences. Theriogenology 6:575-583.

Rajala-Schultz PJ and Gröhn YT. 1999. Culling of dairy cows. Part III. Effects of diseases, pregnancy status and milk yield on culling in Finnish Ayrshire cows. Prev. Vet. Med. 41:295309.

Roche JF, Mackey D, Diskin MD. 2000. Reproductive management of postpartum cows. Anim. Reprod. Sci. 60-61:703712.

Rounsaville TR, Oltenacu PA, Milligan RA, Foote RH. 1979. Effects of heat detection, conception rate, and culling policy on reproductive performance in dairy herds. J. Dairy Sci. 62: 1435-1442.

Shrestha HK, Nakao T, Higaki T, Suzuki T, Akita M. 2004a. Resumption of postpartum ovarian cyclicity in high-producing Holstein cows. Theriogenology 61:637-649.

Shrestha HK, Nakao T, Suzuki T, Higaki T, Akita M. 2004b. Effects of abnormal ovarian cycles during pre-service period postpartum on subsequent reproductive performance of high-producing Holstein cows. Theriogenology 61:15591571.

Staples CR, Thatcher WW, Clark JH. 1990. Relationship between ovarian activity and energy status during the early postpartum period of high producing dairy cows. J. Dairy Sci. 73:938-947.

Villa-Godoy A, Hughes TL, Emery RS, Chapin LT, Fogwell RL. 1988. Association between energy balance and luteal func- 
tion in lactating dairy cows. J. Dairy Sci. 71:1063-1072.

Wiltbank M, Lopez H, Sartori R, Sangsritavong S, Gümen A.

2006. Changes in reproductive physiology of lactating dairy cows due to elevated steroid metabolism. Theriogenology 65:17-29. 